\title{
The effect of emulsifying salts on the turbidity of a diluted milk system with varying $\mathrm{pH}$ and protein concentration
}

\author{
M. D. Culler, Y. Saricay, and F. M. Harte ${ }^{1}$ \\ Department of Food Science, the Pennsylvania State University, University Park 16802
}

\section{ABSTRACT}

Solutions of 10 commonly used emulsifying salts (ES) listed in the Code of Federal Regulations (21CFR133.179) for pasteurized process cheese were tested for their effect on the turbidity of a diluted milk system at different $\mathrm{pH}$ and protein concentrations to characterize the conditions that affect micellar structure. Emulsifying salt solutions were made by mixing the ES in a 1-in-20 dilution of water in skim milk ultrafiltrate (3 $\mathrm{kDa}$ molecular weight cut-off) to obtain ES concentrations from 0 to $248 \mathrm{~m} M$. Skim milk was added to solutions containing nanopure water, skim milk ultrafiltrate, and a specific ES ranging in concentration from 0 to $248 \mathrm{~m} M$ and $\mathrm{pH} 5,5.8,6.8,7.8$, and 8.8. The turbidity of the samples was measured as the optical density at $400 \mathrm{~nm}$ immediately after mixing (time, $\mathrm{t}=$ $0)$, after $30 \mathrm{~s}(\mathrm{t}=30 \mathrm{~s})$, and after $30 \mathrm{~min}(\mathrm{t}=30 \mathrm{~min})$. Emulsifying salts were found to cause a decrease in the turbidity of the system, which was modeled using an exponential decay model, where $\mathrm{C}^{*}$ represents a threshold salt concentration at which rapid dissociation occurs. At $\mathrm{pH}$ values 5.8 and 6.8 , the $\mathrm{ES}$ caused the greatest decrease in turbidity of the diluted milk system. At $\mathrm{pH} 5$, the ES had the least effect on the turbidity of the system. Sodium hexametaphosphate was found to have the strongest dissociative effect, with a $\mathrm{C}^{*}$ value of $0.33 \mathrm{~m} M$ for $\mathrm{t}=0$ at $\mathrm{pH} 6.8$. In contrast, the largest $\mathrm{C}^{*}$ value calculated at $\mathrm{pH} 6.8$ was monosodium phosphate at $278.22 \mathrm{mM}$. Increased time resulted in lower $\mathrm{C}^{*}$ values. The model established for this study can be used to predict the dissociation of casein micelles in the presence of various types of ES.

Key words: emulsifying salt, process cheese, turbidity, micellar structure

\section{INTRODUCTION}

Although emulsifying salts (ES) are essential in the manufacturing of processed cheese for melting unifor-

Received January 3, 2017.

Accepted February 9, 2017.

${ }^{1}$ Corresponding author: fede@psu.edu mity, texture, spreadability, and oiliness, the specific chemistry behind their mechanism of action is still under investigation. So far, our understanding of the effect that the $13 \mathrm{ES}$ listed in the Code of Federal Regulations (CFR; 21CFR133.169) will have on the physical properties of cheese has relied on empirically observing the outcome of the final products (Mounsey and O'Riordan, 1999; Kaliappan and Lucey, 2011). To replace the current trial-and-error approach that governs the usage of ES, a deeper understanding of the physicochemical effects and functional attributes of ES is required. As the effects of ES become better understood, manufacturers will have an easier time adopting their usage for specific applications, such as meeting the demand for clean label products.

It is well documented both that the action of the ES is to affect the structure of casein micelles present in cheese and that the ES chelate calcium from the micelle, causing the micelles to dissociate (Holt et al., 2003; Kaliappan and Lucey, 2011). In processed cheese, these dissociated, amphiphilic proteins move to the interfaces between the fat molecules and aid with emulsification (Dickinson, 1999; Awad et al., 2002). Thus, the ES used in the manufacture of processed cheese are not emulsifiers themselves but cause emulsification in the cheese system through their dissociating influence on caseins (Carić et al., 1985; Kaliappan and Lucey, 2011). Different ES have varied effects on the calcium distribution as well as the final cheese product (McIntyre et al., 2016). The exact structure of the casein micelle is not known; however, it is commonly depicted as a spherical quaternary protein structure with more hydrophilic $\kappa$-caseins surrounding an inner layer of more hydrophobic $\alpha$-and $\beta$-caseins. Also present inside the casein micelle is colloidal calcium phosphate, an ionic complex that serves as the "glue" that helps hold the individual casein proteins together in a micelle along with hydrophobic interactions (Holt, 2016).

Individual ES are known to produce different effects in the final cheese product (Kaliappan and Lucey, 2011). Tetrasodium diphosphate (TSDP) has been found to have properties unique from other phosphate salts that are affected by a critical ES concentration in the system (Shirashoji et al., 2016). In the case of phosphates, the 
distribution of charges on phosphate and casein molecules and the $\mathrm{p} K_{\mathrm{a}}$ values all contribute to the potential for ES-protein interaction. These ES might play a role similar to salts in the Hofmeister series that work at the protein-water interface to change the conformation of the protein due to interaction with the water (Stankey et al., 2011). Some salts in the Hofmeister series (perchlorate, nitrate, and bromide) have been found to be misplaced in terms of the dissociative effects that they have on $\beta$-casein (Sawyer and Puckridge, 1973). The authors concluded that individual proteins are likely to vary in their susceptibility to dissociation by chaotropic salts; they also concluded that temperature, $\mathrm{pH}$, and the protein concentration of the system will determine the amount of salt needed to cause dissociation.

Emulsifying salts mentioned in the CFR can be classified into the following groups: monophosphates, condensed phosphates, glassy (long-chain) phosphates, citrates, and tartrates. A general trend in the calcium chelating ability of some of the ES has been established as monophosphate $<$ citrate $<$ diphosphate $<$ hexametaphosphate (Van Wazer and Callis, 1958). Several roles have been established for the ES. The first is their calcium-binding ability, which has a very significant effect on the properties of the cheese because it is thought that an ideal ES consists of the combination of a monovalent/divalent cation with a polyvalent ion (Guinee et al., 2004). The ability of a salt, specifically an ES, to bind $\mathrm{Ca}^{2+}$ depends on the valence, type of ion species formed, $\mathrm{pH}$, ionic strength, and temperature (Kaliappan and Lucey, 2011). The direct binding of phosphate ES, especially sodium hexametaphosphate (SHMP), to positively charged amino acid residues and the indirect binding via calcium bridges have also been suggested as potential action mechanisms (Mizuno and Lucey, 2005; de Kort, 2012).

Turbidity measurements have been established as a way to indirectly examine the aggregation and dissociation of casein micelles (Parker and Dalgleish, 1977; Orlien et al., 2010; Kaliappan and Lucey, 2011). Because casein micelles are primarily responsible for the white color, or turbidity, in skim milk or casein powder solutions, a decrease in turbidity is due to a dissociation of the casein micelles into smaller structures. This method has been used to confirm that the turbidity of a solution containing casein micelles decreases as the ES dissociate the micelles (Pitkowski et al., 2008; Orlien et al., 2010; Anema and Klostermeyer, 1997). Turbidity measurements have also been used to show that increasing pressure causes a decrease in micellar aggregation at varying temperatures and $\mathrm{pH}$ levels (de Kort, 2012).

The aim of this paper was to examine and model the effect that ES have on the structural integrity of casein micelles by measuring their turbidity in a diluted skim milk system at various $\mathrm{pH}$ levels over time. This wide range of salts, concentrations, and $\mathrm{pH}$ levels examined over time have been chosen to generate a body of data to directly compare the different effects between ES.

\section{MATERIALS AND METHODS}

\section{Materials}

Monosodium phosphate [MSP, molecular weight (MW): 119.98 Da; CAS no. 7558-80-7], trisodium phosphate (TSP, MW: 163.96 Da; CAS no. 7601-549), sodium acid diphosphate (SAD; MW: 221.94 Da; CAS no. 7758-16-9, listed in the CFR as sodium acid pyrophosphate), sodium tartrate (ST, MW: 230.08 Da; CAS no. 6106-24-7), disodium phosphate (DSP, MW: 141.96 Da; CAS no. 7558-79-4), calcium citrate (CC, MW: 570.49 Da; CAS no. 5785-44-4), and sodium potassium tartrate (SPT, MW: 282.22 Da; CAS no. 6381-59$5)$ were obtained from Sigma-Aldrich (St. Louis, MO). Dipotassium phosphate (DPP, MW: 174.18 Da; CAS no.7758-11-4) and sodium citrate (SC, MW: 294.1 Da; CAS no. 6132-04-3) were obtained from VWR (Radnor, PA). Sodium hexametaphosphate (MW: 611.77 Da; CAS no. 10124-56-8) and TSDP (MW: 265.9 Da; CAS no. 7722-88-5, listed in the CFR as tetrasodium pyrophosphate) were obtained from Alfa Aesar (Ward Hill, MA). Potassium citrate (PC, MW: 306.396 Da; CAS no. 6100-05-6) and sodium aluminum phosphate (SAP, MW: 221.94 Da; CAS no. 10305-76-7) were obtained from Spectrum Chemical MFG Corp. (New Brunswick, NJ). Pasteurized, homogenized skim milk was obtained from the Berkey Creamery at the Pennsylvania State University (University Park).

\section{Sample Preparation}

Stock solutions of each ES were prepared at $250 \mathrm{mM}$ by adding the appropriate weight of ES to a 1-in-20 dilution of protein-free serum (PFS) in water. Proteinfree serum was obtained using a 3-kDa tangential flow regenerated cellulose filtration filter (Prep/Scale Spiral Cartridge, Millipore, Darmstadt, Germany). The $\mathrm{pH}$ of the stock ES solutions was adjusted using small quantities of $\mathrm{NaOH}$ or $\mathrm{HCl}$ as appropriate to $\mathrm{pH} 5,5.8,6.8$, 7.8, and 8.8. These stock solutions were further diluted using pH-adjusted, 1-in-20 PFS-in-water solutions to create ES concentrations of $0,0.1,1,5,10,15,25,50$, 100 , and $248 \mathrm{~m} M$. Milk samples for $\mathrm{pH} 5,5.8,6.8$, and 7.8 were adjusted using small amounts of $1 \mathrm{M} \mathrm{HCl}$ or $\mathrm{NaOH}$ as appropriate at least $2 \mathrm{~h}$ before experimentation and were again measured and adjusted as necessary. In a separate experiment, MSP and DPP were 


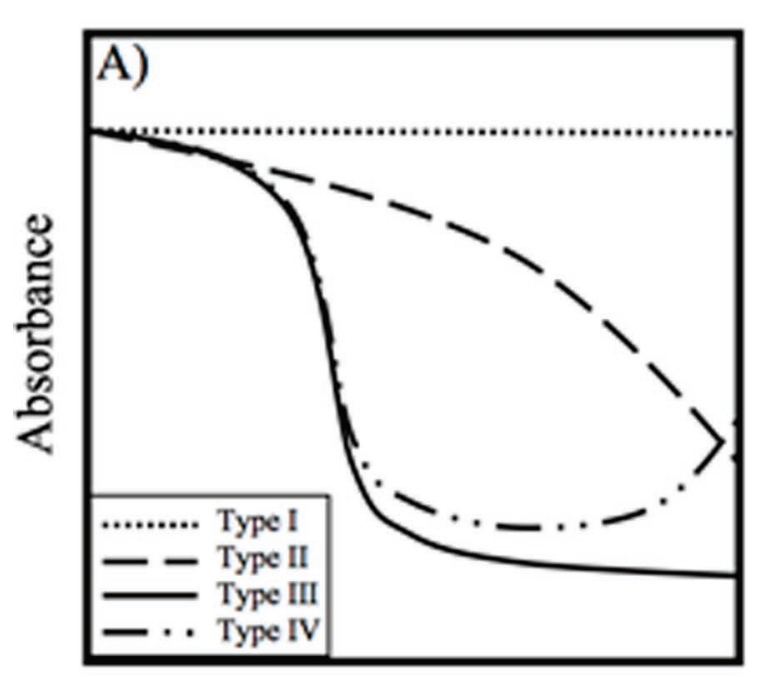

$[\mathrm{ES}](\mathrm{mM})$

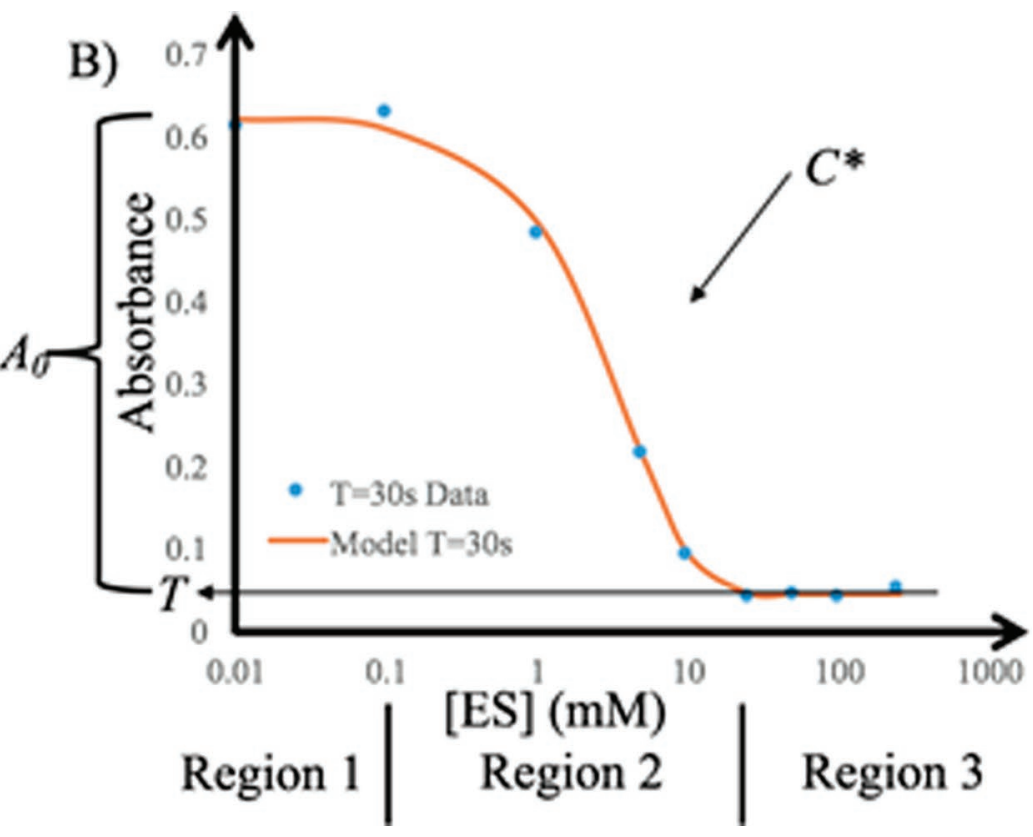

Figure 1. (A) The 4 trends observed in absorbance versus emulsifying salt (ES) concentration; (B) type III is shown with the variables in Equation [1]. The data points (blue) represent the data shown from sodium acid diphosphate at time $t=30 \mathrm{~s}$; the curve (orange) shows the modeled data using Equation [1]: $y=\left(A_{0}+T\right) e^{-C_{\text {salt }} / C^{*}}+T$, where $y$ is the dependent variable, $A_{0}$ is the difference between the initial turbidity of the diluted skim milk solution (without addition of ES) and the final turbidity (at the highest ES concentration), $T$ is the final or residual turbidity, $C$ is the ES concentration present in solution, and $C^{*}$ represents the inflection point of the curve. Color version available online.

Average Starting Turbidity (0 $\mathrm{m} M$ Salt)

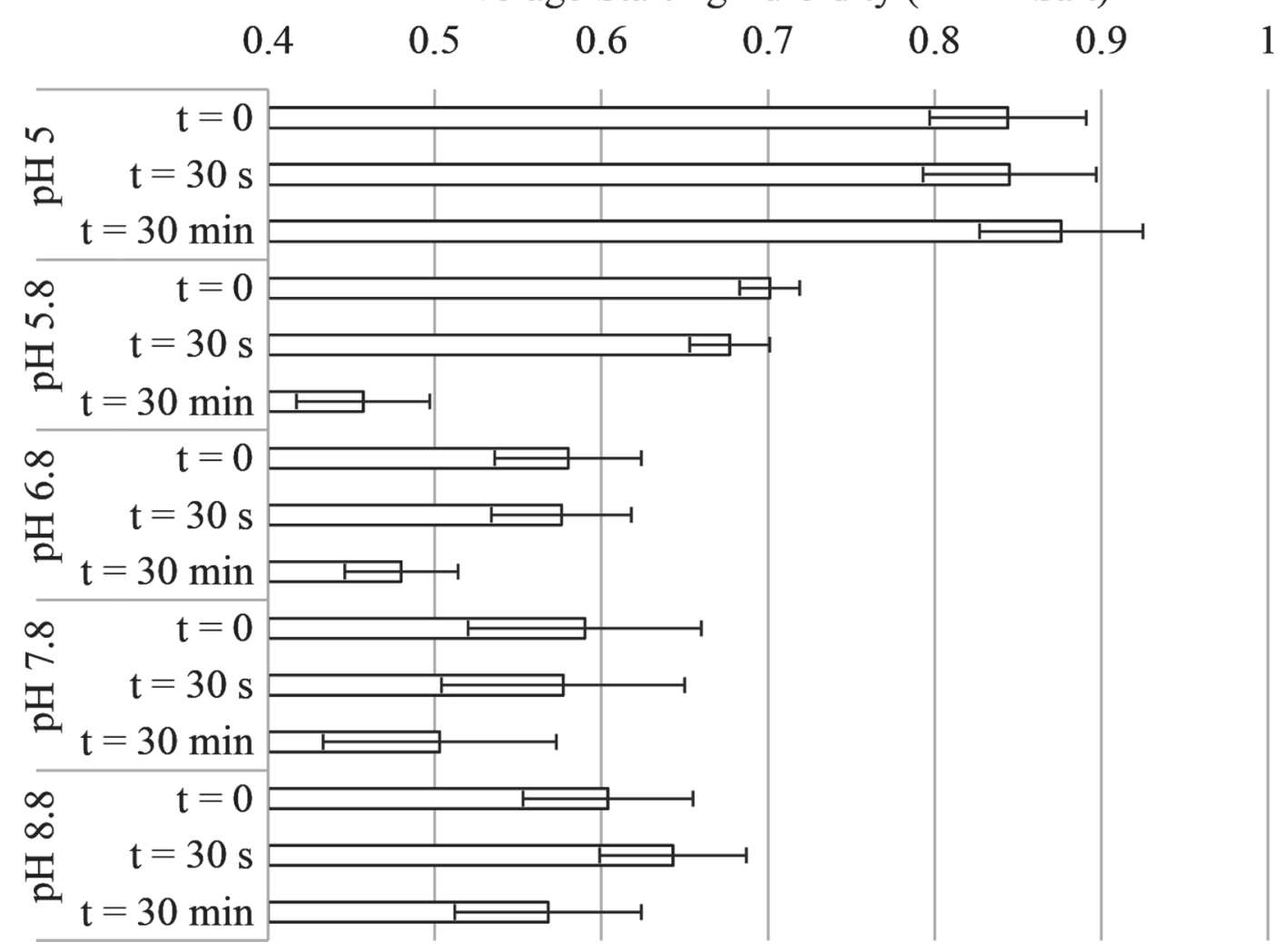

Figure 2. Average turbidity values for diluted milk at $0 \mathrm{~m} M$ salt concentration as affected by $\mathrm{pH}$ and time. Bars are standard deviations. 
separately measured at concentrations up to $1 M$. For experiments with varying protein contents, ultrafiltration retentate and permeate were used in varying ratios to obtain concentrations of 1.4, 2.8, 4.2, and 5.6\% (wt/ wt) casein. All sample preparation and experimentation was performed at room temperature.

\section{Turbidity Measurements}

Turbidity was defined as the optical density at 400 $\mathrm{nm}$ (Genesys 10S UV-Vis, ThermoFisher Scientific, Waltham, MA) and measured by adding $40 \mu \mathrm{L}$ of skim milk to $1,940 \mu \mathrm{L}$ of a given ES solution and pipette mixed. Measurements were made immediately after mixing $(\mathrm{t}=0 \mathrm{~s})$, after $30 \mathrm{~s}(\mathrm{t}=30 \mathrm{~s})$, and after $30 \mathrm{~min}$ $(\mathrm{t}=30 \mathrm{~min})$. At $\mathrm{pH} 8.8$, the turbidity of milk was observed to change over time without the addition of ES, so TSP, SHMP, PC, and ST were chosen to represent a range of ES types and characteristic turbidity curves to be measured immediately after $\mathrm{NaOH}$ was added to the milk to control for the turbidity change. Measurements were performed in duplicate, and the results presented represent the average of the 2 replicates. The starting milk turbidities (at $0 \mathrm{mM}$ ES) from each curve were pooled by $\mathrm{pH}$ and time before measurement to calculate the average, standard deviation, and coefficient of variation for each group of experiments.

\section{Modeling}

The data were modeled for each $\mathrm{pH}$ level and time by fitting Equation [1] to the data as shown in Figure 1:

$$
y=\left(A_{0}+T\right) e^{-C_{\text {salt }} / C^{*}}+T
$$
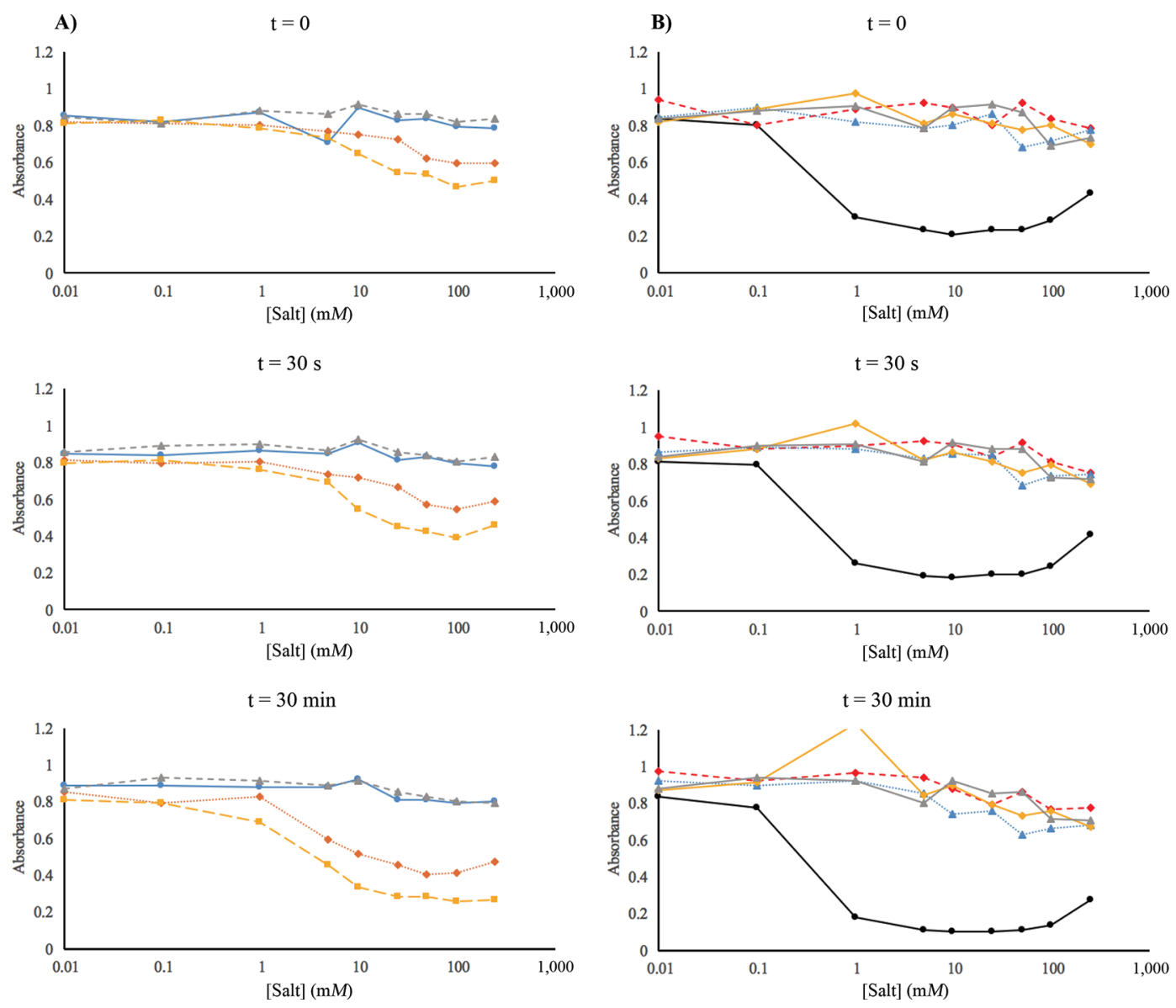

Figure 3. Turbidity curves of diluted milk at various salt concentrations tested at $\mathrm{pH} 5.0$ at time $(\mathrm{t})=0 \mathrm{~s}, \mathrm{t}=30 \mathrm{~s}, \mathrm{t}=30 \mathrm{~min}$. Samples without salt were reported as 0.01 in the logarithmic scale. (A) Monosodium phosphate (- - - , disodium phosphate (--- ---$)$, dipotassium phosphate (-----), and trisodium phosphate (- --$)$; and (B) sodium hexametaphosphate (- - ), sodium acid diphosphate (--- --$)$, sodium citrate $(\cdots \cdots)$, potassium citrate $(--)$, sodium tartrate $(-\mathbf{\Delta}-)$, sodium potassium tartrate $(-----)$. Sodium potassium tartrate was insoluble at $250 \mathrm{mM}$ at $\mathrm{pH} 5$, so testing was not performed for this salt at these conditions. Color version available online. 
where $y$ is the dependent variable, $A_{0}$ is the difference between the initial turbidity of the diluted skim milk solution (without addition of ES) and the final turbidity (at the highest ES concentration), $T$ is the final or residual turbidity, $C$ is the $\mathrm{ES}$ concentration present in solution, and $C^{*}$ represents a threshold ES millimolar concentration for the amount of ES needed to cause a large amount of dissociation of the micelles (region 2 in Figure 1). When an uptick in turbidity happened at ES concentrations approaching $250 \mathrm{mM}$, the points forming the uptick were excluded from the model. Additionally, in cases in which adding ES to a concentration of $248 \mathrm{~m} M$ did not cause at least a $30 \%$ decrease in the turbidity of the sample, the minimum values obtained in region 3 of Figure 1 for SHMP at that $\mathrm{pH}$ were used for $T$. This decision was made on the assumption that if ES concentration was increased beyond $250 \mathrm{mM}$, a decrease in the turbidity of the system would eventually occur. The $\mathrm{C}^{*}$ values that were calculated to be greater than 2 times the concentration of ES used in this study were not reported.

\section{RESULTS AND DISCUSSION}

\section{Overview}

The turbidity versus ES concentration graphs were grouped into 4 general response types shown in Figure 1. Type I ES were defined as those for which turbidity did not decrease by at least $30 \%$ of the initial turbidity with the addition of $248 \mathrm{~m} M$ ES. Type II ES had a greater than $30 \%$ decrease in turbidity, but never reached the final flat phase that was seen in type III graphs. Finally, type IV graphs showed an uptick in turbidity at high ES concentrations. Different ES produced different types of graphs depending on $\mathrm{pH}$ and time (discussed later).
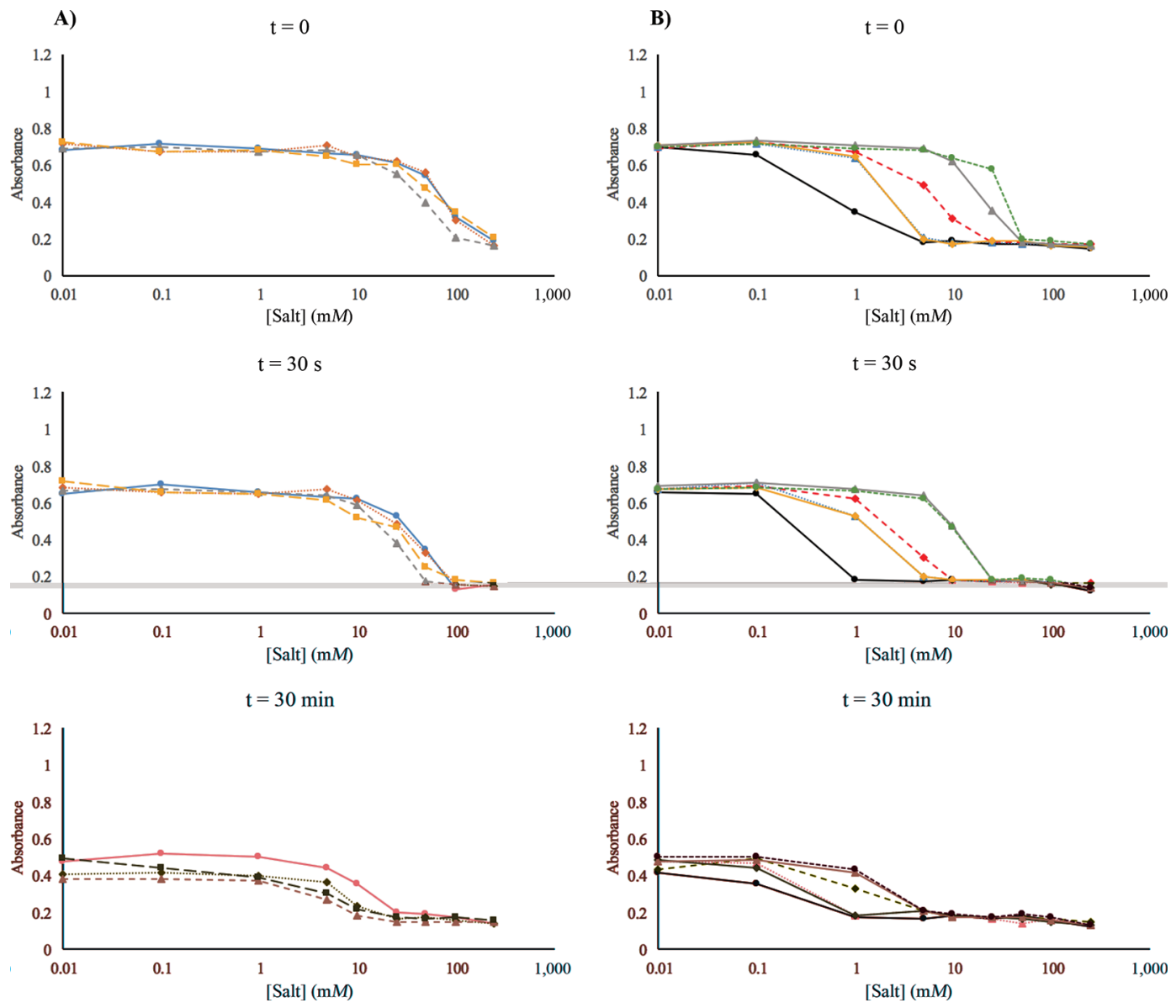

Figure 4. Turbidity curves of diluted milk at various salts concentrations tested at $\mathrm{pH} 5.8$ at time $(\mathrm{t})=0 \mathrm{~s}, \mathrm{t}=30 \mathrm{~s}, \mathrm{t}=30 \mathrm{~min}$. Samples without salt were reported as 0.01 in the logarithmic scale. (A) Monosodium phosphate (- - ), disodium phosphate (--- -- ), dipotassium

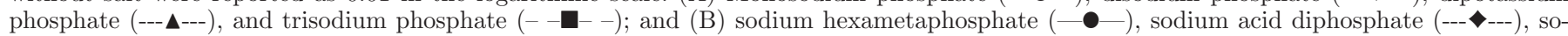
dium citrate $\left(\cdots \mathbf{\Lambda}^{\cdots}\right)$, potassium citrate $(--)$, sodium tartrate $(-\mathbf{\Lambda})$, sodium potassium tartrate (-----). Color version available online. 


\section{Effect of Emulsifying Salt Type and Concentration}

Because TSDP, SAP, and CC were not soluble at 250 $\mathrm{m} M$, no further experimentation was performed using these ES. Sodium potassium tartrate was insoluble at $\mathrm{pH} 5$; however, $\mathrm{pH}$ levels of 5.8, 6.8, and 7.8 were analyzed for this ES. For experiments that were performed, a relatively low experimental error was observed among replications (Figure 2). Standard deviations were calculated from the initial turbidity values $(0 \mathrm{mM}$ ES in the system) from a given $\mathrm{pH}$ and time. A maximum 0.07 standard deviation was calculated for absorbance values and maximum coefficient of variance ranging from 11.9 to $13.9 \%$ for experiments at $\mathrm{pH}$ 7.8. For all other $\mathrm{pH}$ levels, the coefficients of variation were well under $10 \%$.

Figures 3, 4, 5, 6, and 7 show the effects of the 10 ES examined in this study on the turbidity of casein micelles as their concentrations were increased from 0 to $248 \mathrm{mM}$ at varying $\mathrm{pH}$ and time.

The ES were grouped based on the turbidity trends that were exhibited in response to an increase in their concentration. Mono-, di-, and tri-sodium phosphates in Figure 5A caused a decrease in turbidity at concentrations approaching $250 \mathrm{mM}$; however, they failed to cause sufficient dissociation at $t=0$ to reach the flat region characteristic of the turbidity curves in Figure 5B for hexametaphosphate, diphosphate, citrates, and tartrates.

The calculated threshold ES concentrations $\left(\mathrm{C}^{*}\right)$ based on an exponential decay model at pH 6.8 (Figure 8) varied greatly depending on the type of ES that was used. In fact, ES type was the single greatest factor in determining the $\mathrm{C}^{*}$ values in this study. For MSP, DSP, TSP, and DPP, the ES concentrations used in this study were not sufficient to reach the minimum
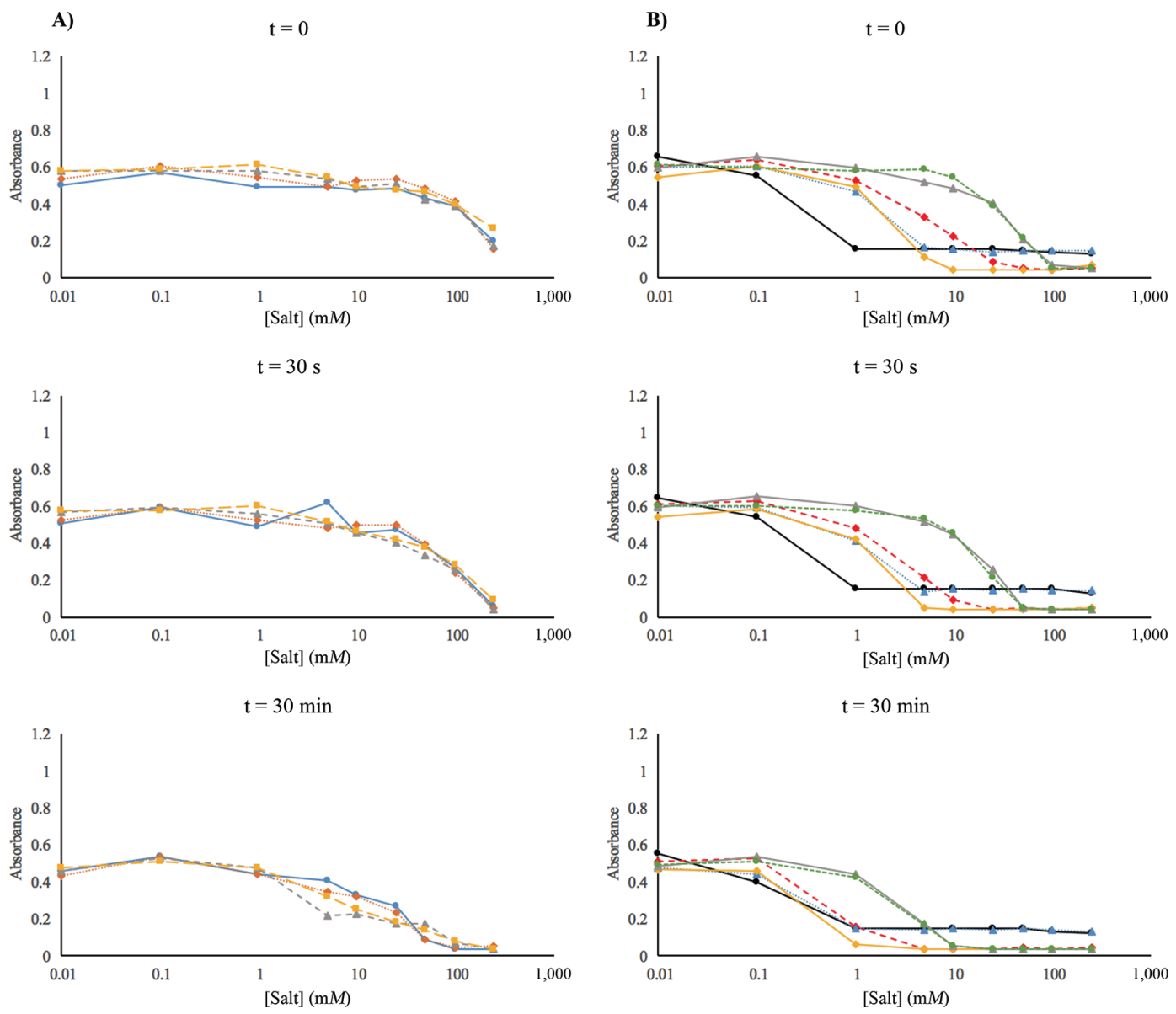

Figure 5. Turbidity curves of diluted milk at various salt concentrations tested at $\mathrm{pH} 6.8$ at time $(\mathrm{t})=0 \mathrm{~s}, \mathrm{t}=30 \mathrm{~s}, \mathrm{t}=30 \mathrm{~min}$. Samples without salt were reported as 0.01 in the logarithmic scale. (A) Monosodium phosphate (- - ), disodium phosphate (--- ---$)$, dipotassium phosphate (--- ---$)$, and trisodium phosphate $\left(--_{-}\right)$; and (B) sodium hexametaphosphate $(-\bullet-)$, sodium acid diphosphate (--- --$)$, sodium citrate $(\cdots \boldsymbol{\wedge})$, potassium citrate $(--)$, sodium tartrate $(-\mathbf{\Delta}-)$, sodium potassium tartrate $\left(---\bullet_{---)}\right.$. Color version available online. 
turbidities observed at high concentrations of other ES. The ES were modeled with the assumption that if ES concentrations were increased higher than tested (and possibly beyond solubility limits), they would eventually reach region 3 in Figure 1. In some cases, this assumption resulted in $\mathrm{C}^{*}$ values greater than double the actual ES concentrations used in this study. For these cases, the $\mathrm{C}^{*}$ value is simply reported as being greater than $500 \mathrm{~m} M$.

Almost all $\mathrm{R}^{2}$ values for the models were well above 0.9 , indicating that the exponential decay model was representative of the curves induced by ES. Previous authors found a sigmoidal decrease in the turbidity of a skim milk system when increasing hydrostatic pressure was applied, and they used a similar model to represent their data (Orlien et al., 2010). Thus, it appears that increasing pressure and increasing ES concentration have very similar effects with regard to turbidity in skim milk systems.

The $\mathrm{C}^{*}$ value for SHMP at $\mathrm{pH} 6.8$ and $\mathrm{t}=0$ was 0.33 $\mathrm{m} M$, making it the most efficient $\mathrm{ES}$ at decreasing the turbidity of the system. This finding is in agreement with previous work that examined the effect of linear SHMP (with average phosphate chain length of 5.6) on a model system containing milk protein concentrate (Mizuno and Lucey, 2005). In that experiment with SHMP, DSP, TSDP, and TSC, SHMP was observed to be the strongest at dissociating the micelles. By comparison, DSP caused a relatively small decrease in the turbidity of the system. This outcome is in general agreement with the finding in this study that MSP, DSP, and DPP caused a similar decrease in the turbidity of the solution, with $\mathrm{C}^{*}$ values ranging from 278 $\mathrm{m} M$ for MSP to $216 \mathrm{~m} M$ for DPP at $\mathrm{pH} 6.8$ and $\mathrm{t}$
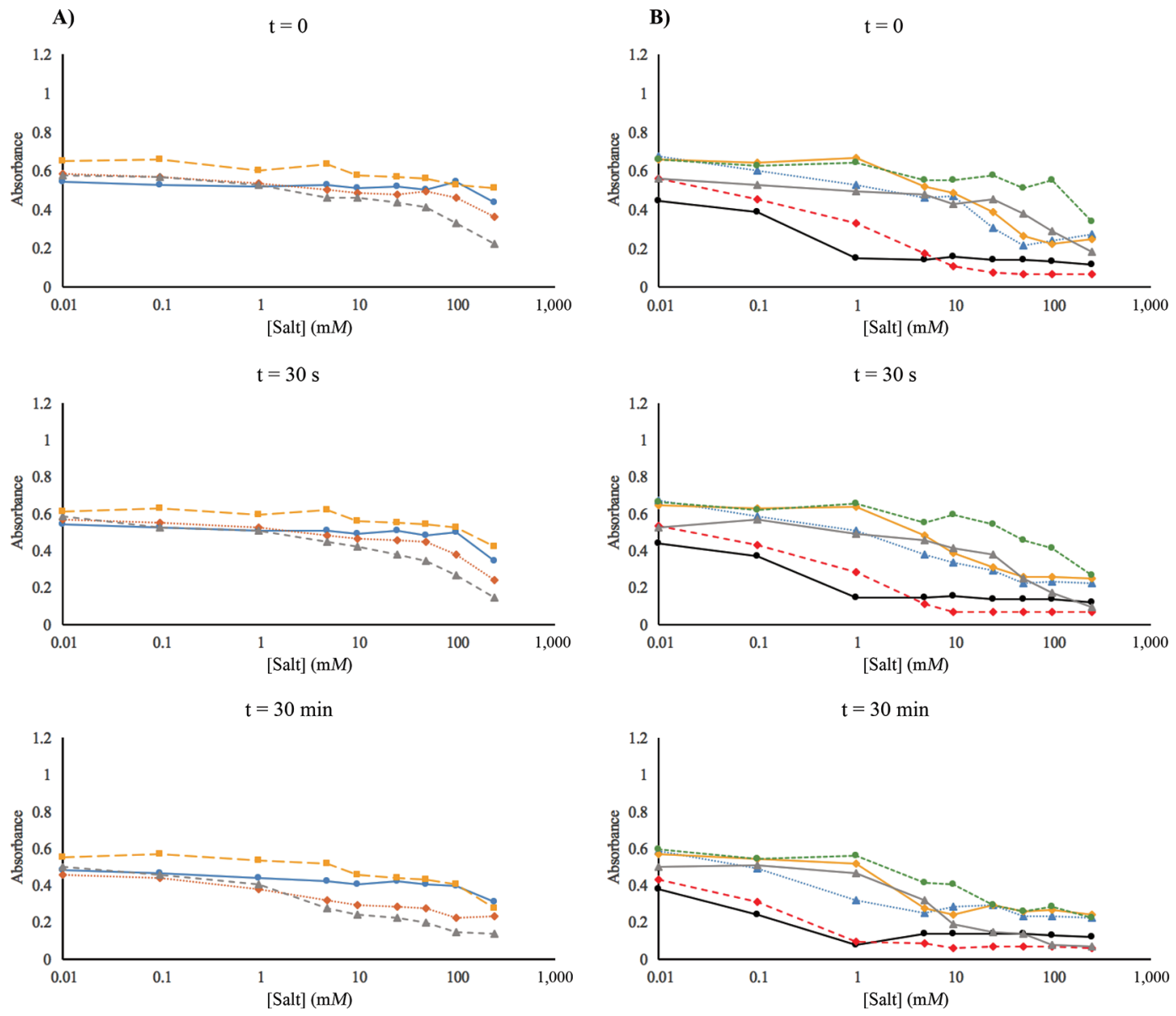

Figure 6. Turbidity curves of diluted milk at various salt concentrations tested at $\mathrm{pH} 7.8$ at time $(\mathrm{t})=0 \mathrm{~s}, \mathrm{t}=30 \mathrm{~s}, \mathrm{t}=30 \mathrm{~min}$. Samples without salt were reported as 0.01 in the logarithmic scale. (A) Monosodium phosphate (- - - ), disodium phosphate (--- ---$)$, dipotassium phosphate (--- $\left.\mathbf{\Delta}_{---}\right)$, and trisodium phosphate $\left(-\mathbf{-}_{-}-\right)$; and (B) sodium hexametaphosphate $(-\bullet-)$, sodium acid diphosphate $\left(----_{--}\right)$, sodium citrate $(\cdots \mathbf{\Lambda})$, potassium citrate $(-\longrightarrow)$, sodium tartrate $(-\mathbf{-}-)$, sodium potassium tartrate $(-----)$. Color version available online. 
$=0$. However, concentrations up to $250 \mathrm{~m} M$ were not sufficient to reach the final horizontal phase (Region 3 in Figure 1) that was seen at higher concentrations for the remaining $\mathrm{ES}$ at $\mathrm{t}=0$. The 2 citrate salts $(\mathrm{SC}$ and $\mathrm{PC}$ ) and the 2 tartrate salts (ST and SPT) tested in this study behaved similarly in pairs, with $\mathrm{C}^{*}$ values of $2.2,2.9,43$, and $47 \mathrm{mM}$, respectively.

\section{Effect of Time}

Allowing the ES to have more time to interact with the milk system caused the $\mathrm{C}^{*}$ values to decrease for almost every ES, $\mathrm{pH}$, and time tested. This result is shown for each $\mathrm{pH}$ level tested in Figure 8. A strong example of this phenomenon is TSP for which the $\mathrm{C}^{*}$ values decreased over time from $\sim 122$ to $\sim 106 \mathrm{mM}$ and then to $\sim 13 \mathrm{mM}$. As the $\mathrm{C}^{*}$ values decreased, the type of graph (as described in Figure 1) formed by each ES also shifted in most cases, as described in Table 1. In every case in which the type of graph formed by an ES changed, the shift followed the pattern of going from type I, through II and III, to IV. This finding suggests that given more time or possibly higher concentrations of ES, more of the type I and II responses would have become type III responses. Because the uptick in type IV responses are probably due to the formation of new aggregates (discussed later), not all ES necessarily possess the characteristics to cause a type IV response.

The turbidities of the solutions decreased rapidly after milk was combined with an ES, and the change became more gradual later. This result can best be seen by looking at the time intervals between $\mathrm{t}=0$ to $\mathrm{t}=$ $30 \mathrm{~s}$ and $\mathrm{t}=30 \mathrm{~s}$ to $\mathrm{t}=30 \mathrm{~min}$ in Figure 8, where for most ES a comparable amount of dissociation took place in the first $30 \mathrm{~s}$ compared with what occurred in the subsequent $30 \mathrm{~min}$. Some ES, such as SHMP, experienced minimal percent change in the 30-min segment, which was likely because the ES had already induced full dissociation.

\section{Effect of $p H$}

Figures 3 to 7 show the turbidity curves for $\mathrm{pH} 5.0$, $5.8,6.8,7.8$, and 8.8 , respectively. The $\mathrm{pH}$ had a very strong effect on the $\mathrm{C}^{*}$ value as well as the shape of the turbidity curve. A change in $\mathrm{pH}$ was also found to affect the initial turbidity of the diluted system without any ES being present. The turbidity values for the system, which can be seen in Figure 2, show that the milk became more turbid as the $\mathrm{pH}$ decreased. For ES at $\mathrm{pH} 5$ (Figure 3), the average starting turbidity was 0.844; whereas at $\mathrm{pH} 7$, the starting turbidity dropped to 0.586 . This outcome is expected because caseins display less aggregation as $\mathrm{pH}$ becomes higher, away from their isoelectric point (Horne, 1998). At pH 5, the $\mathrm{C}^{*}$ values were the highest on average, with most ES exhibiting $\mathrm{C}^{*}>500 \mathrm{~m} M$ (Figure 8). This finding is also demonstrated by the abundance of type I responses, as shown in Figure 3 and Table 1.

Sinaga et al. (2017) previously established that as caseins approach their isoelectric point, their structure becomes more compact. Furthermore, when caseins are acidified to $\mathrm{pH} 5.2$, part of the calcium and all
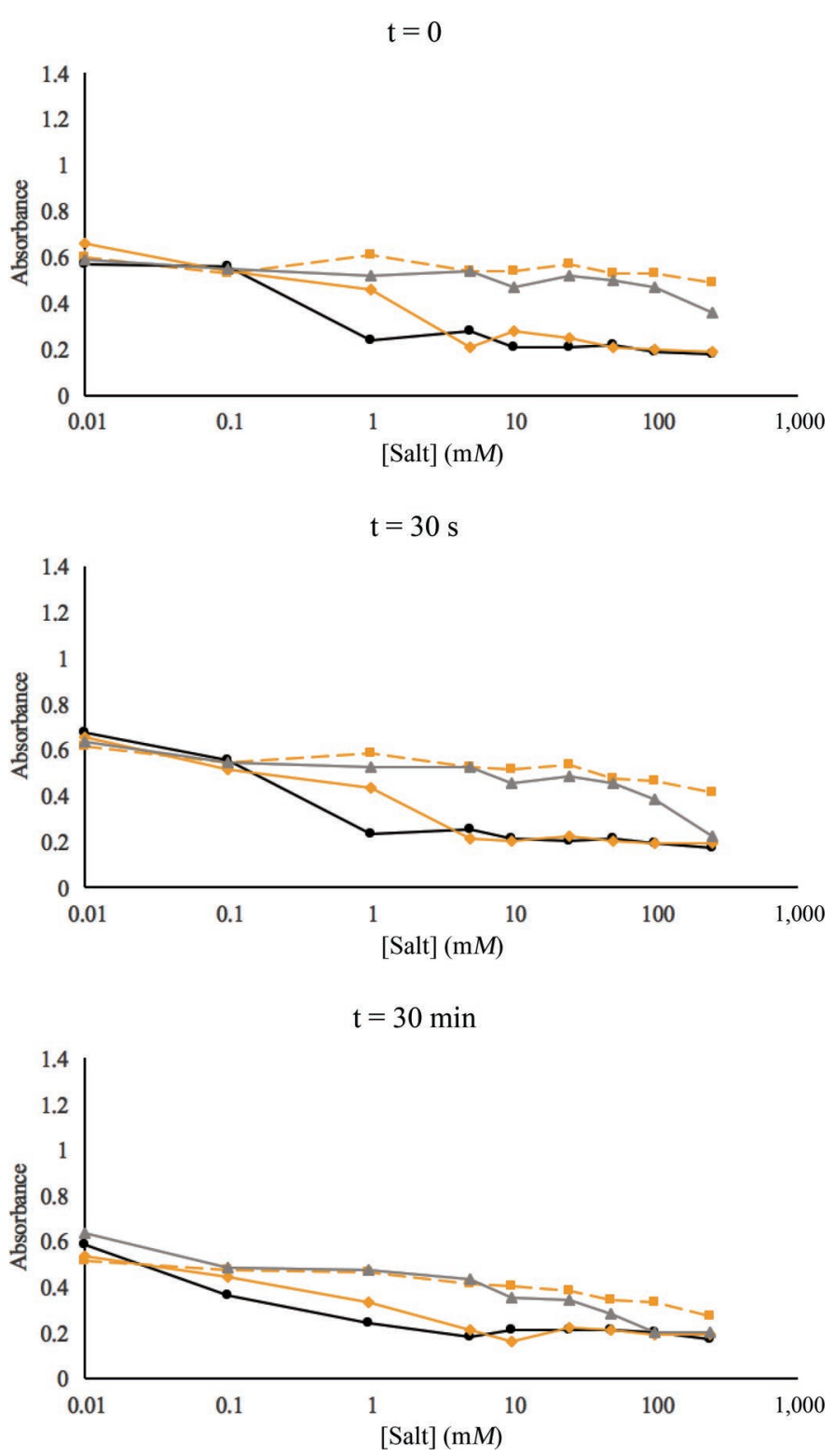

Figure 7. Turbidity curves of diluted milk at various salt concentrations tested at $\mathrm{pH} 8.8$ at time $(\mathrm{t})=0 \mathrm{~s}, \mathrm{t}=30 \mathrm{~s}, \mathrm{t}=30 \mathrm{~min}$. Samples without salt were reported as 0.01 in the logarithmic scale. Shown are results from trisodium phosphate $(\boldsymbol{\square})$, sodium hexametaphosphate $(\bullet)$, potassium citrate $(\bullet)$, and sodium tartrate $(\boldsymbol{\Delta})$. Color version available online. 
of the inorganic phosphate have been solubilized from the micelle (Broyard and Gaucheron, 2015). A tighter micellar structure that is more reliant on aggregation from protein charge than on calcium phosphate bridges seems to be less susceptible to dissociation caused by calcium chelation of ES. All ES at $\mathrm{pH} 5$ that had $\mathrm{C}^{*}$ values low enough to calculate were phosphate salts. The $\mathrm{C}^{*}$ values for SHMP were relatively unaffected by $\mathrm{pH}$, which suggests that the amount of calcium in the micelle is unimportant for micellar dissociation from this ES. Further evidence for this conclusion is pro- vided by the previous finding (Sinaga et al., 2017) that SHMP can interact with casein without the presence of calcium.

\section{Aggregate Formation}

To better study the behavior of ES at high concentrations, MSP and DPP were added in concentrations up to $1 M$ at $\mathrm{pH}$ 6.8. The results, which are shown in Figure 9 , were similar to the turbidity increases observed for SHMP and DSP at $250 \mathrm{mM}$ at $\mathrm{pH}$ 5. These upticks

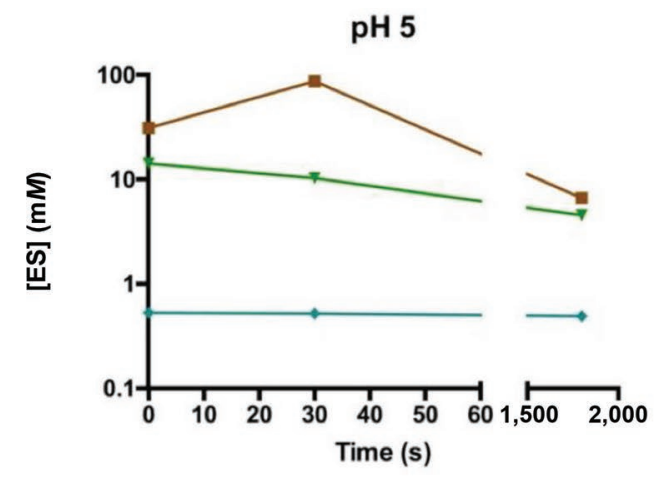

pH 5.8

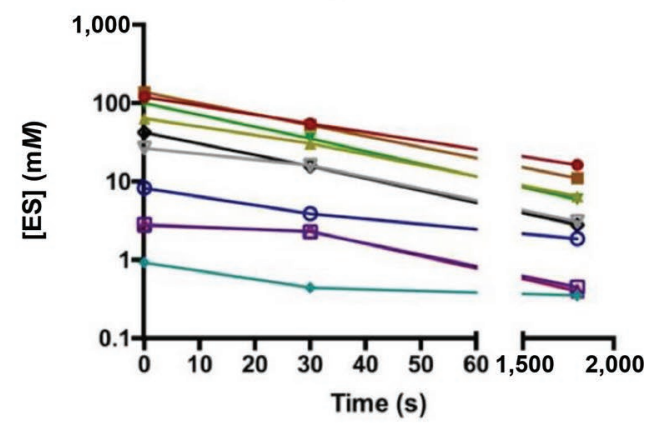

pH 6.8

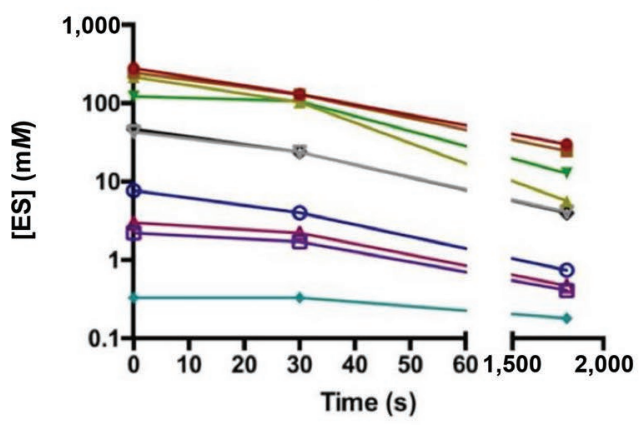

pH 7.8

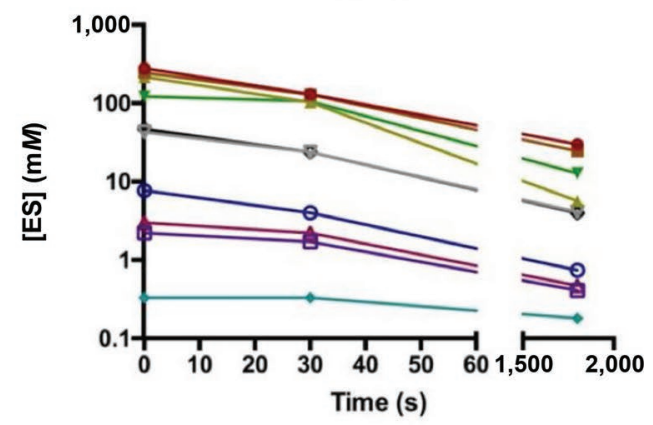

pH 8.8

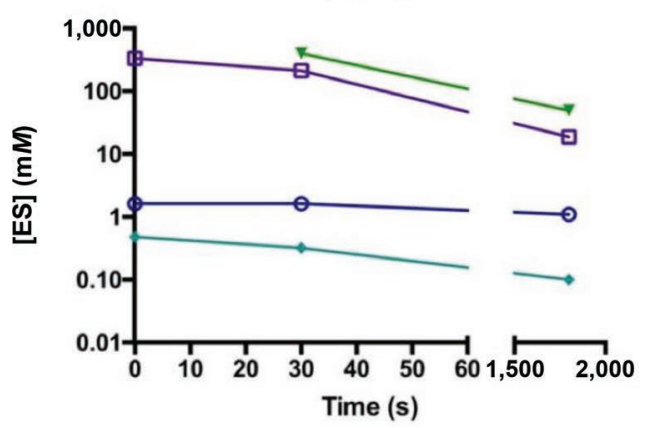

Figure 8. Critical salt concentration $\left(\mathrm{C}^{*}, \mathrm{~m} M\right)$ grouped by $\mathrm{pH}$ for monosodium phosphate $(\bullet)$, disodium phosphate $(\mathbf{\square})$, dipotassium phosphate $(\boldsymbol{\Lambda})$, trisodium phosphate $(\boldsymbol{\nabla})$, sodium hexametaphosphate $(\bullet)$, sodium acid diphosphate $(\bigcirc)$, sodium citrate, $(\square)$, potassium citrate $(\triangle)$, sodium tartrate $(\nabla)$, sodium potassium tartrate $(\diamond)$. No values are reported when the model predicted $\mathrm{C}^{*}>250 \mathrm{~m} M$. Trisodium phosphate, sodium hexametaphosphate, potassium citrate, and sodium tartrate were the only salts tested at $\mathrm{pH} 8.8$. At $\mathrm{pH} 5$, sodium potassium tartrate was not soluble at $250 \mathrm{mM}$. ES = emulsifying salts. Color version available online. 
Table 1. Depending on the $\mathrm{pH}$, salt type, and time (t), the shape of the turbidity curve (see Figure 1) changed for each salt ${ }^{1}$

\begin{tabular}{|c|c|c|c|c|c|c|c|c|c|c|}
\hline \multirow[b]{2}{*}{ Variable } & \multicolumn{10}{|c|}{ Salt type ${ }^{2}$} \\
\hline & MSP & DSP & DPP & TSP & SHMP & $\mathrm{SAD}$ & $\mathrm{SC}$ & $\mathrm{PC}$ & $\mathrm{ST}$ & SPT \\
\hline \multicolumn{11}{|l|}{$\overline{\mathrm{pH} 5}$} \\
\hline $\mathrm{t}=0 \mathrm{~s}$ & I & III & I & III & IV & I & I & I & I & $\mathrm{NA}^{3}$ \\
\hline $\mathrm{t}=30 \mathrm{~s}$ & I & IV & I & III & IV & I & I & I & I & NA \\
\hline $\mathrm{t}=30 \min$ & I & IV & I & III & IV & I & I & I & I & NA \\
\hline \multicolumn{11}{|l|}{ pH 5.8} \\
\hline $\mathrm{t}=0 \mathrm{~s}$ & II & II & II & II & III & III & III & III & III & III \\
\hline $\mathrm{t}=30 \mathrm{~s}$ & III & III & III & II & III & III & III & III & III & III \\
\hline $\mathrm{t}=30 \min$ & III & III & III & III & III & III & III & III & III & III \\
\hline \multicolumn{11}{|l|}{ pH 6.8} \\
\hline $\mathrm{t}=0 \mathrm{~s}$ & II & II & II & II & III & III & III & III & III & III \\
\hline $\mathrm{t}=30 \mathrm{~s}$ & II & II & II & II & III & III & III & III & III & III \\
\hline $\mathrm{t}=30 \min$ & III & III & II & II & III & III & III & III & III & III \\
\hline \multicolumn{11}{|l|}{ pH 7.8} \\
\hline $\mathrm{t}=0 \mathrm{~s}$ & I & II & II & I & III & III & III & III & II & II \\
\hline $\mathrm{t}=30 \mathrm{~s}$ & II & II & II & II & III & III & III & III & II & II \\
\hline $\mathrm{t}=30 \mathrm{~min}$ & II & III & III & II & III & III & III & III & III & III \\
\hline \multicolumn{11}{|l|}{ pH 8.8} \\
\hline $\begin{array}{l}\mathrm{t}=0 \mathrm{~s} \\
\mathrm{t}=30 \mathrm{~s}\end{array}$ & NA & NA & NA & 1 & III & $\mathrm{NA}$ & NA & III & II & NA \\
\hline $\mathrm{t}=30 \mathrm{~min}$ & NA & NA & NA & II & III & NA & NA & III & II & NA \\
\hline & NA & 10 & $1 \mathrm{NA}$ & 11 & III & NA & NA & 111 & III & NA \\
\hline
\end{tabular}

${ }^{1}$ Type I emulsifying salt (ES) curves decreased by less than $30 \%$ of their initial turbidity with the addition of $248 \mathrm{~m} M$ ES. Type II ES had a greater than $30 \%$ decrease in turbidity, but never reached the final flat phase that was seen in type III graphs. Type IV graphs showed an uptick in turbidity at high ES concentrations.

${ }^{2} \mathrm{MSP}=$ monosodium phosphate DSP $=$ disodium phosphate; $\mathrm{DPP}=$ dipotassium phosphate; $\mathrm{TSP}=$ trisodium phosphate; SHMP = sodium hexametaphosphate; $\mathrm{SAD}=$ sodium acid diphosphate; $\mathrm{SC}=$ sodium citrate; $\mathrm{PC}=$ potassium citrate ST = sodium tartrate; $\mathrm{SPT}=$ sodium potassium tartrate.

${ }^{3} \mathrm{NA}=$ not applicable; not tested in this experiment.

in turbidity could potentially represent the formation of new casein-ES structures. These increases in turbidity were unlikely to be the result of the ES coming out of solution at high concentrations because it was confirmed before experimentation that all stock ES solutions were clear and that no ES precipitates or sedimentation were present. The idea of interaction between the ES and the proteins is supported by previous findings that once SHMP has dissociated the casein micelles, the protein, calcium, and phosphate can re-associate to form new complexes that cause a thick gel (Mizuno and Lucey, 2005). Furthermore, zeta potential measurements have confirmed that SHMP can directly form a complex with casein in the absence of calcium (de Kort, 2012). Because these ES did initially experience a decrease in turbidity, it seems likely that a minimum ES concentration exists that must be present in the system before re-aggregation can begin to occur.

\section{Effect of Protein Concentration}

The effect of protein concentration was tested on TSP, SHMP, PC, and ST to get a representation of phosphate salts with different effects on turbidity as well as citrate and tartrate salts. The $\mathrm{C}^{*}$ values did not change significantly based on protein concentration at the concentrations tested in this study (1.4 to 5.6\% wt/wt casein; data not shown). Because the system had such a small amount of protein, it is possible that doubling the protein content did not cause a significant enough shift in the ES-to-protein ratio to see sufficient changes.

\section{CONCLUSIONS}

The sigmoidal decrease in turbidity in the diluted skim milk system studied here can be modeled accurately using an exponential decay model as shown in Equation [1]. An increase in the critical concentration $\mathrm{C}^{*}$, which was found to represent a threshold concentration at which turbidity rapidly decreases, was observed when the system was allowed to interact for increased time or when the $\mathrm{pH}$ of the system was moved closer to $\mathrm{pH}$ 5.8. At high concentrations of SHMP, DPP, MSP, and DSP, turbidity increased, which could indicate the formation of new aggregates in the system. Testing ES in this manner allows for results that are directly comparable. With these results, it was possible to see that adding extra time for the system to react caused the turbidity profiles to shift from type I to type II and then to type 


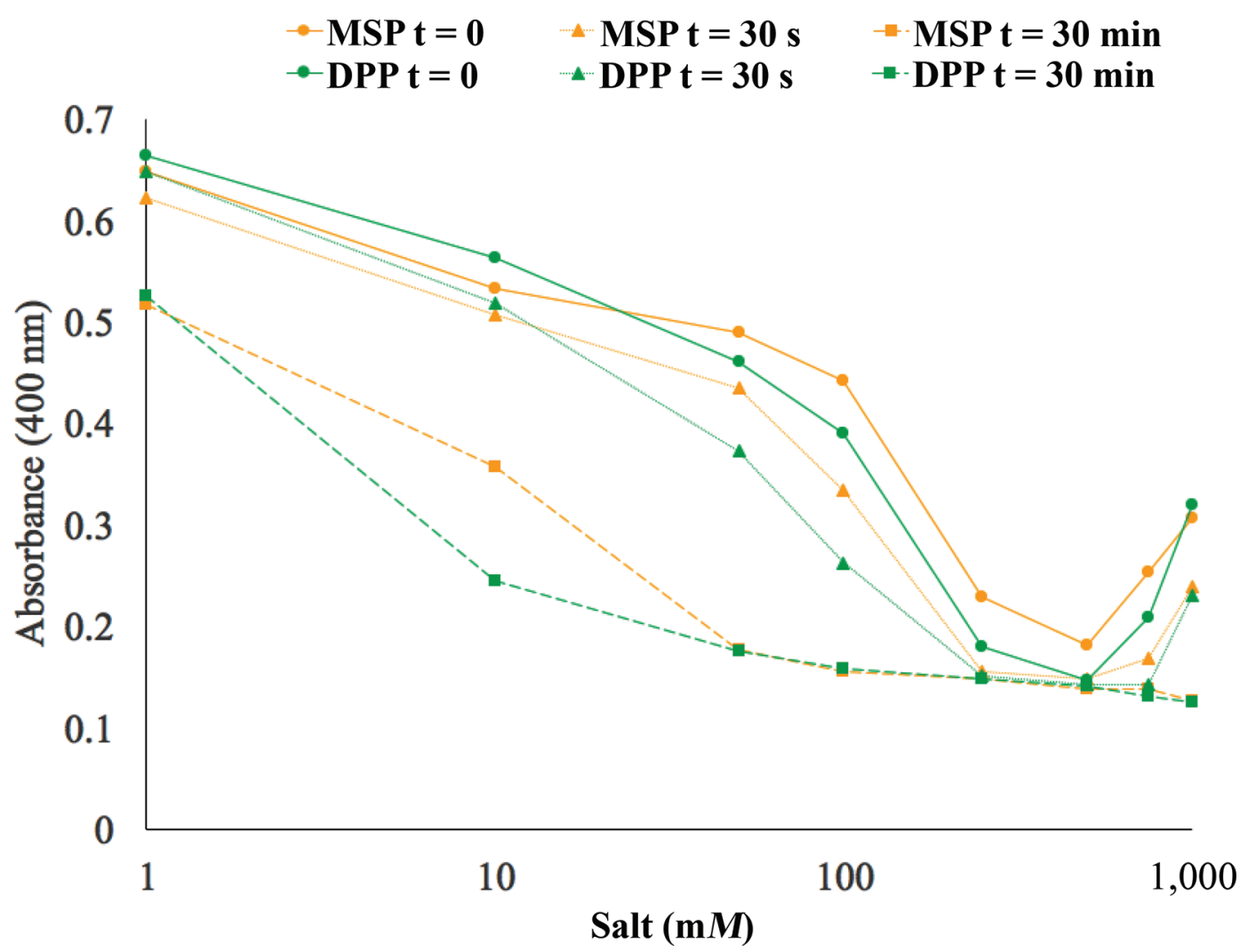

Figure 9. Effect of high concentration of salts monosodium phosphate (MSP) and dipotassium phosphate (DPP) on the turbidity of diluted milk at $\mathrm{pH}$ 6.8. $\mathrm{t}=$ time. Color version available online.

III, and in some cases, to type IV graphs. Further testing is required to determine the protein conformation of these aggregates.

\section{ACKNOWLEDGMENTS}

The authors acknowledge the Pennsylvania State University (University Park) and the National Dairy Council (Rosemont, IL) through project "Prototype to study the effect of ionic environments on casein micelle integrity" for providing funding for this research.

\section{REFERENCES}

Anema, S. G., and H. Klostermeyer. 1997. Heat-induced, pH-dependent dissociation of casein micelles on heating reconstituted skim milk at temperatures below $100{ }^{\circ} \mathrm{C}$. J. Agric. Food Chem. 45:11081115. https://doi.org/10.1021/jf960507m.

Awad, R. A., L. B. Abdel-Hamid, S. A. El-Shabrawy, and R. K. Singh. 2002. Texture and microstructure of block type processed cheese with formulated emulsifying salt mixtures. LWT Food Sci. Technol. (Campinas) 35:54-61. https://doi.org/10.1006/fstl.2001.0828.

Broyard, C., and F. Gaucheron. 2015. Modifications of structures and functions of caseins: A scientific and technological challenge. Dairy Sci. Technol. 95:831-862. https://doi.org/10.1007/s13594-0150220-y.
Carić, M., M. Gantar, and M. Kalab. 1985. Effects of emulsifying agents on the microstructure and other characteristics of process cheese-A review. Food Struct. 4:297-312.

de Kort, E. 2012. Influence of calcium chelators on concentrated micellar casein solutions: from micellar structure to viscosity and heat stability. PhD Dissertation. Wageningen University, Wageningen, the Netherlands.

Dickinson, E. 1999. Caseins in emulsions: Interfacial properties and interactions. Int. Dairy J. 9:305-312. https://doi.org/10.1016/ S0958-6946(99)00079-5.

Guinee, T. P., M. Carić, and M. Kaláb. 2004. Pasteurized processed cheese and substitute/imitation cheese products. Cheese Chem. Phys. Microbiol. 2:349-394. https://doi.org/10.1016/S1874$558 \mathrm{X}(04) 80052-6$.

Holt, C. 2016. Casein and casein micelle structures, functions and diversity in 20 species. Int. Dairy J. 60:2-13. https://doi.org/10.1016/j. idairyj.2016.01.004.

Holt, C., C. de Kruif, R. Tuinier, and P. Timmins. 2003. Substructure of bovine casein micelles by small-angle X-ray and neutron scattering. Colloids Surf. A Physicochem. Eng. Asp. 213:275-284. https://doi.org/10.1016/S0927-7757(02)00520-4.

Horne, D. S. 1998. Casein interactions: Casting light on the black boxes, the structure in dairy products. Int. Dairy J. 8:171-177. https://doi.org/10.1016/S0958-6946(98)00040-5.

Kaliappan, S., and J. A. A. Lucey. 2011. Influence of mixtures of calcium-chelating salts on the physicochemical properties of casein micelles. J. Dairy Sci. 94:4255-4263. https://doi.org/10.3168/ jds.2010-3343.

McIntyre, I., M. O' Sullivan, and D. O' Riordan. 2016. Effects of calcium chelators on calcium distribution and protein solubility in rennet casein dispersions. Food Chem. 197:233-239. https://doi. org/10.1016/j.foodchem.2015.10.084 
Mizuno, R., and J. A. Lucey. 2005. Effects of emulsifying salts on the turbidity and calcium-phosphate-protein interactions in casein micelles. J. Dairy Sci. 88:3070-3078. https://doi.org/10.3168/jds. S0022-0302(05)72988-X.

Mounsey, J. S., and E. D. O'Riordan. 1999. Empirical and dynamic rheological data correlation to characterize melt characteristics of imitation cheese. J. Food Sci. 64:701-703. https://doi. org/10.1111/j.1365-2621.1999.tb15114.x.

Orlien, V., L. Boserup, and K. Olsen. 2010. Casein micelle dissociation in skim milk during high-pressure treatment: Effects of pressure, $\mathrm{pH}$, and temperature. J. Dairy Sci. 93:12-18. https://doi. org/10.3168/jds.2009-2244.

Parker, T. G., and D. G. Dalgleish. 1977. The use of light-scattering and turbidity measurements to study the kinetics of extensively aggregating proteins: $\alpha$ s-Casein. Biopolymers 16:2533-2547. https://doi.org/10.1002/bip.1977.360161115.

Pitkowski, A., T. Nicolai, and D. Durand. 2008. Scattering and turbidity study of the dissociation of casein by calcium chelation. Biomacromolecules 9:369-375. https://doi.org/10.1021/bm7006899.
Sawyer, W. H., and J. Puckridge. 1973. The dissociation of proteins by chaotropic salts. J. Biol. Chem. 248:8429-8433.

Shirashoji, N., H. Aoyagi, J. J. Jaeggi, and J. A. Lucey. 2016. Effect of tetrasodium pyrophosphate concentration and cooking time on the physicochemical properties of process cheese. J. Dairy Sci. 99:6983-6994. https://doi.org/10.3168/jds.2016-10968.

Sinaga, H., N. Bansal, and B. Bhandari. 2017. Effects of milk $\mathrm{pH}$ alteration on casein micelle size and gelation properties of milk Int. J. Food Prop. 20:179-197. https://doi.org/10.1080/10942912 .2016 .1152480 .

Stankey, J. A., M. E. Johnson, and J. A. Lucey. 2011. Effect of selected Hofmeister salts on textural and rheological properties of nonfat cheese. J. Dairy Sci. 94:4264-4276. https://doi.org/10.3168/ jds.2010-3698.

Van Wazer, J. R., and C. F. Callis. 1958. Metal complexing by phosphates. Chem. Rev. 58:1011-1046. https://doi.org/10.1021/ cr50024a001. 